\title{
Study on color removal of Sewage Treatment Plant (STP) effluent using granular activated carbon
}

\author{
Anita Nurfida, I Nyoman Widiasa* \\ Chemical Engineering Department, Diponegoro University, Semarang, Indonesia
}

\begin{abstract}
Recycling of sewage treatment plant (STP) effluent is one of the attractive solutions to fulfill clean water for hotels and malls in Indonesia. STP effluent has average characteristics as follow: $\mathrm{pH}$ 6.8; color (true color) $107 \mathrm{PtCo}$; $\mathrm{A}_{254}$ (UV absorption) $0.36 \mathrm{~cm}^{-1}$ and COD $35.9 \mathrm{mg} / \mathrm{L}$. Because of high color and organics contents, STP effluent needs further treatment such as activated carbon adsorption. Batch and continuous treatment of synthetic STP effluent by a commercial granular activated carbon (Filtrasorb 300) were investigated. The results show that adsorption capacity of the Filtrasorb 300 for color body of STP effluent was $184 \mathrm{PCU} / \mathrm{g}$ of carbon. Langmuir model is appropriate to describe the isotherm adsorption process in this study, with $Q_{m}$ : $476.2 \mathrm{PCU} / \mathrm{g}$ of carbon. The results of isotherm adsorption model evaluation, SEM photograph and FTIR analysis show that color adsorption occurred was physical adsoption.
\end{abstract}

\section{Introduction}

Construction of hotels and malls have been increasing enthusiasticly in major cities in Indonesia such as Jakarta, Bandung, Yogyakarta and Bali. That phenomenon is not complemented with the availability of fresh water supply. Recycling of Sewage Treatment Plant (STP) effluent is one of the solutions in order to fulfill clean water supply for hotels and malls in Indonesia. After being processed, STP effluent are generally used for toilet flushing water [1] and watering the garden, irrigation, fire extinguishing and cooling tower [2]. STP effluent that has characteristics of $\mathrm{pH}$, color (true color), $\mathrm{A}_{254}$ (UV absorption), and COD respectively $6.8 ; 107 ; 0.36 \mathrm{~cm}^{-1} ; 35.9 \mathrm{mg} / \mathrm{L} \mathrm{[3]}$, is a potential alternative source of clean water. Since its color and organic content are still high, advanced wastewater treatment is required. Color in STP effluent is caused by humic substances as a result of contact between water and Natural Organic Matter (NOM) [4]. Dissolved ions in water such as iron $(\mathrm{Fe})$ and manganese (Mn) [5] can also contribute the color.

The adsorption process using activated carbon is one of the most frequently method to remove color and organic pollutants in water and wastewater. Mostly, color removal process is applied in the textile wastewater [5-9] since it generates high color waste. Organics removal in the STP effluent using activated carbon adsorption has been widely applied [10-15], but study on its color removal is still slighty done [3]. Color removal process is needed to meet the requirements of water quality set by the Ministry of Health No.
416/MENKES/Per/IX/1990 which the maximum amount is $50 \mathrm{TCU}$.

The objective of this paper is to determine the contact time and maximum adsorption capacity for color removal in the STP effluent. In the adsorption process, the contact time plays an important role for achieving maximum adsorption capacity, relating to the materials transfer to be absorbed into the pores of activated carbon. In addition, this paper aims to determine the isothermic adsorption models that appropriate with the color removal process in STP effluent.

\section{Materials and methods}

\subsection{Preparation of activated carbon}

Granular activated carbon (GAC) was purchased from Calgon (Filtrasorb 300). The GAC was throughly washed using demineralized water in order to clean its impurities. This process was conducted until the turbidity of rinse water below 1 . Then GAC was dried at $105^{\circ} \mathrm{C}$ until the constant weight was achieved. Afterwards, it was stored in a desiccator. Morphological features of carbon were obtained with Scanning Electron Microscope-Electron Dispersive X-Ray (SEM-EDX) Jeol JSM-6510LA, Japan. The specific surface areas was calculated by the Brunauer-Emmett-Teller (BET) method while the pore size distributions (PSD) of the activated carbon particles were obtained using the nitrogen gas adsorption-desorption method with Autosorb-iQ, Quantachrome ASIQC0600-5, USA. The

\footnotetext{
* Corresponding author: widiasa@undip.ac.id
} 
functional group of samples were determined by Fourier transform infrared spectroscopy (FTIR) IR Prestige 21, Shimadzu, Japan.

\subsection{Preparation of synthetic effluent STP}

Synthetic STP effluent was collected from the activated sludge treatment water cultured in wastewater laboratory of Chemical Engineering, Diponegoro University. As analogy of STP effluent, the activated sludge was settled for 30 minutes. The synthetic STP effluent has characteristics of $\mathrm{pH}$, color (true color), and COD respectively $6,59-115 \mathrm{PCU}$, and $31-93 \mathrm{mg} / \mathrm{L}$. The effluent water characteristics was vary, depends on the prior biological treatment process (activated sludge).

\subsection{Experimental procedure}

\subsubsection{Batch adsorption tests}

Isotherm adsorption experiments were carried out by shaking $100 \mathrm{~mL}$ sample solution with activated carbon in $250 \mathrm{~mL}$ erlenmeyer flasks. Activated carbon (0,25-2 g) were immediately added to each flasks, and they were shaken on a rotary shaker at a constant temperature and $150 \mathrm{rpm}$ constant velocity for 10-120 minute, which had been previously determined to be the time required to reach adsorption equilibrium [16]. All of the samples were extracted by filtering through $0.45 \mu \mathrm{m}$ syringe filters to remove carbon particles. Effect of adsorbent dosage was studied with different adsorbent doses $(0.25-2 \mathrm{~g})$ and $100 \mathrm{~mL}$ of effluent synthetic solution and shaking for equilibrium time. Langmuir and Freundlich equations were employed to study the equilibrium adsorption.

\subsubsection{Continuous adsorption tests}

The adsorption process was conducted in a single set of apparatus consisting of two storage tanks (feed and product), a single centrifugal pump, and a carbon unit contactor (Fig. 1). Synthetic STP effluent as the feed was passed into the GAC contactors using a centrifugal pump while opening BV 02 and BV-03. The feed flow rate was varied by adjusting $\mathrm{BV}-01$ to determine the contact time of the adsorption process. The product water was obtained by opening BV-05. Afterwards, the color and turbidity of product water were analyzed using Multiparameter Photometer HI 83099.

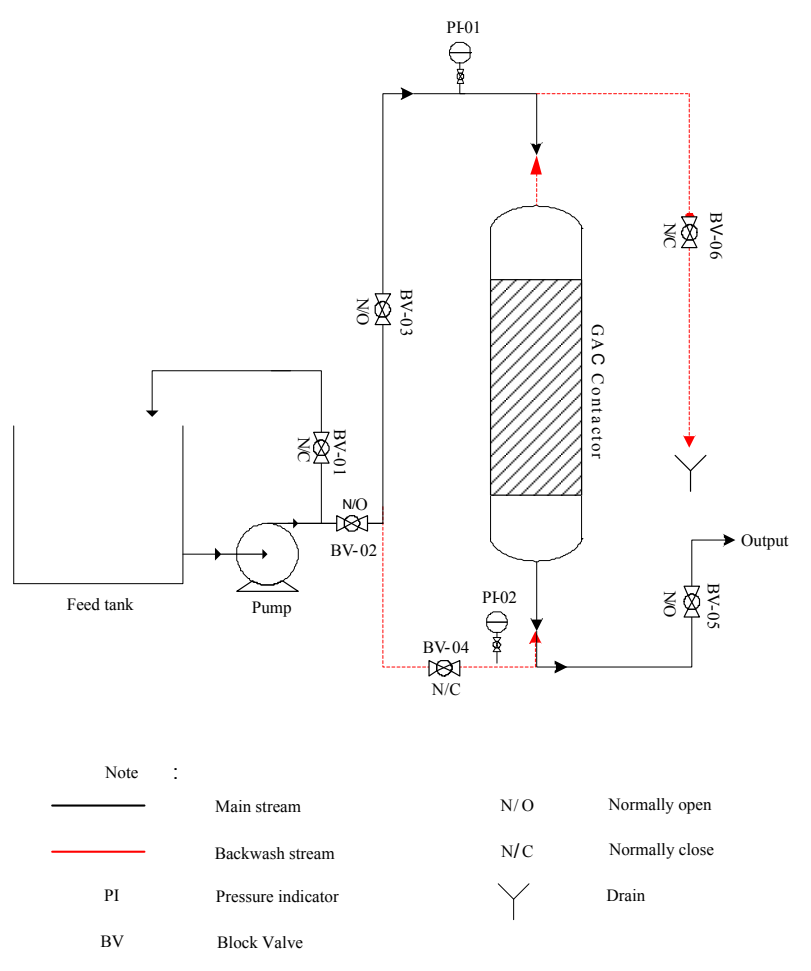

Fig. 1. Scheme of the continuous adsorption test

\section{Result and discussion}

\subsection{Characterization}

\subsubsection{Scanning electron micrograph (SEM) studies}

The aim of activated carbon characterization using SEM was to determine the surface morfology and pore structure of activated carbon. The pore size of activated carbon is divided into 4 types : submicropore $(<0,4 \mathrm{~nm})$, micropore $(<2 \mathrm{~nm})$, mesopore $(2-50 \mathrm{~nm})$ and macropore $(>50 \mathrm{~nm})$. Based on the analysis of SEM at a magnification of $5.000 \mathrm{x}$ (a) and $20.000 \mathrm{x}$ (b), it is obtained that range of the new activated carbon pore size is $89-180 \mathrm{~nm}$, including in the size range mesopore and macropores.
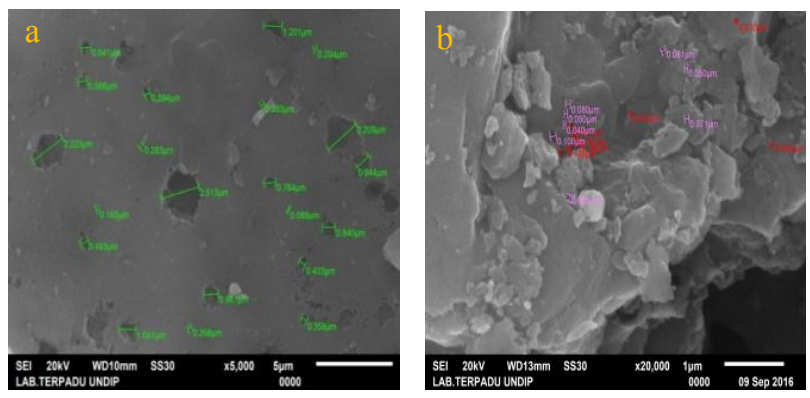

Fig. 2. SEM of new activated carbon

\subsubsection{Brunauer-Emmett-Teller (BET) studies}

Based on the BET analysis, it is obtained that the surface area of activated carbon is $956 \mathrm{~m} 2 / \mathrm{g}$ with a pore radius 
$1.7 \mathrm{~nm}$ and a pore volume of $0.42 \mathrm{cc} / \mathrm{g}$. An average pore diameter of the new activated carbon is $3.4 \mathrm{~nm}$, including the size of the mesoporous. The results of this analysis in accordance with the characteristics of granular activated carbon which has surface area of 700$1300 \mathrm{~m}^{2} / \mathrm{g}$ and a pore radius of $16-30 \AA$ [17].

\subsubsection{FTIR studies}

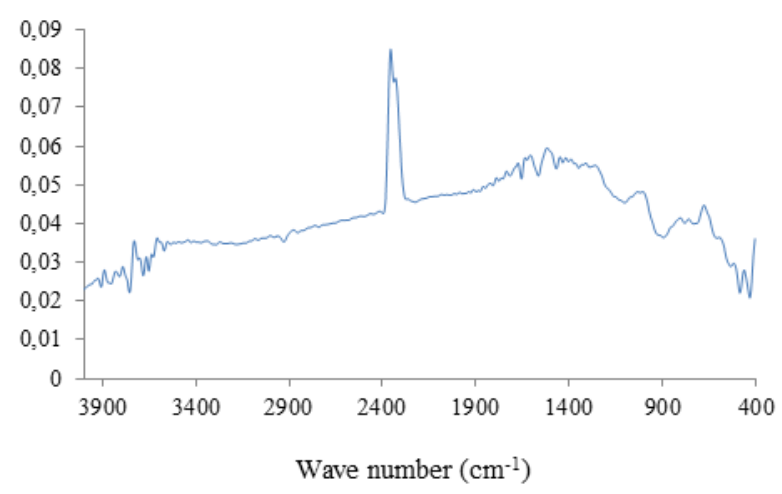

Fig. 3. FTIR new activated carbon

Based on FTIR analysis, the new activated carbon shows sharp peaks around wave number 678-2400 cm-1 (Figure 3). A sharp peak around the wave number of $600-1700 \mathrm{~cm}-1(678.89 \mathrm{~cm}-1)$ indicates the absorption of the carbonyl functional group, amides and carboxylic. While peak located around the wave number of 950$1170 \mathrm{~cm}-1$ is the strain-O functional group $\mathrm{C}$ polysaccharide [18]. The emergence of the peak around the wave number $1200-1280 \mathrm{~cm}-1$ is the group $\mathrm{C}-\mathrm{O}$ strain and deformation $\mathrm{OH} \mathrm{COOH}$ (carboxylic) [18,19]. Another peak is observed in the wave number 1517-1590 $\mathrm{cm}-1$ (1519.86 cm-1) relating to a functional group COO and deformation of the N-H bond [18]. Peak at wave number $1600 \mathrm{~cm}-1(1608.58 \mathrm{~cm}-1)$ is an aromatic functional group $\mathrm{C}=\mathrm{C}$ [19].

\subsection{Batch studies}

Batch adsorption process was carried out in a span of 0-120 minutes. During that time span, the adsorption capacity of activated carbon was investigated until its equilibrium and ultimately it was unable to adsorp anymore. Carbon mass is added to the effluent water of $0.25 ; 0.5 ; 1 ; 1.5$ and 2 grams, this refers to a previous study using carbon dose of 1-10 grams in $100 \mathrm{ml}$ of sample for color removal application in the form of textile waste water [8].

Results of analysis of the colors on the water output can be seen in figure 4 , it appears that the color of the products 58, 34, 18, 12 and 9 PCU with carbon mass 0.25 respectively; $0.5 ; 1 ; 1.5$ and 2 grams.

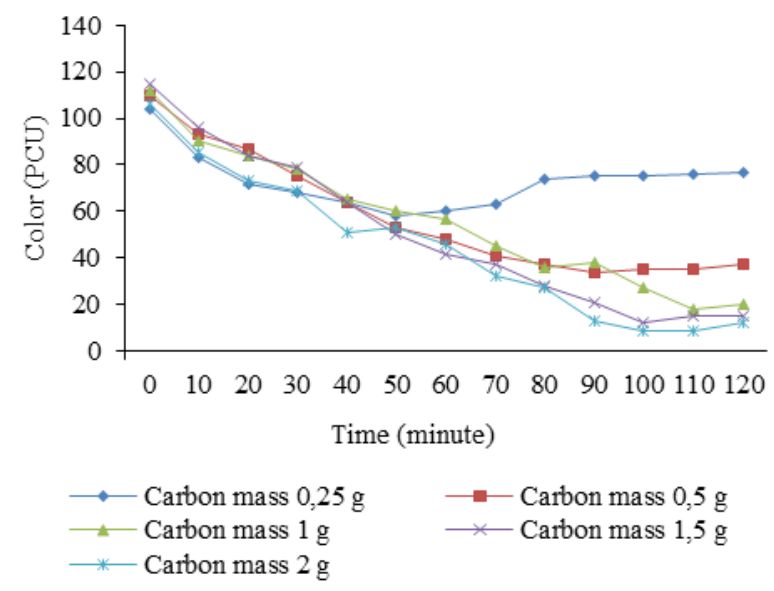

Fig. 4. Water color on various doses of carbon

Water color the resulting product is in conformity with the Ministry of Health less than 50 PCU on carbon mass 0.5 -2 grams. At 0.25 gram mass optimum product color only reached $58 \mathrm{PCU}$, this may be due to the color of the absorbed fraction of excess, while the activated carbon as adsorbent has been exhausted absorptive capacity. A dose of 1 gram of carbon is the most appropriate dose for color removal in this study, it is suspected the fraction of the color components can be absorbed makismal by carbon. Equilibrium occurs at 110-120 minute time span, in which the color components are absorbed not declined against the contact time.

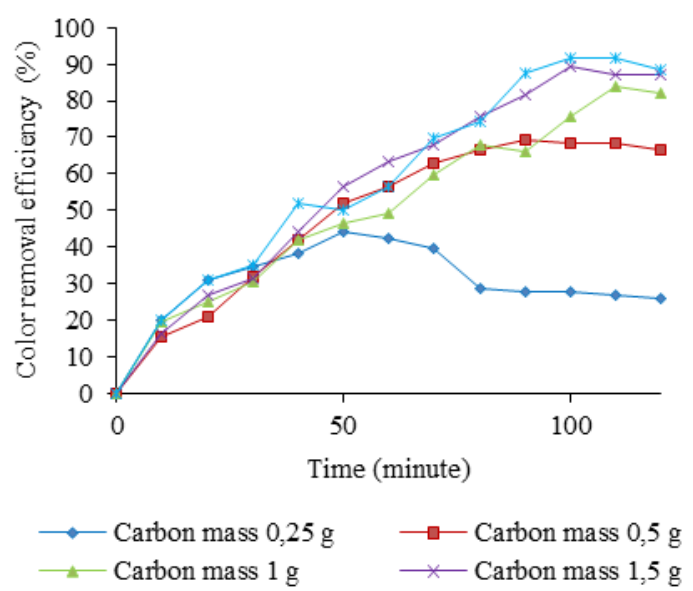

Fig. 5. Color reduction (\%) on various doses of carbon

Color removal efficiency of 4.4 consecutive pictures: $44.23 \% ; 69.09 \% ; 83.93 \% ; 86.96 \%$ and $91.51 \%$ in the carbon mass of $0.25 ; 0.5 ; 1 ; 1.5$ and 2 grams. From the description it appears that the most effective color removal efficiency in carbon mass of 2 grams with an efficiency of $91.51 \%$, which feed water color by 112 PCU and after 100 minutes the adsorption process, the color of the water effluent (product) to 9 PCU. This is because the components / fractions of color in the effluent water is absorbed into the pores of the carbon. 


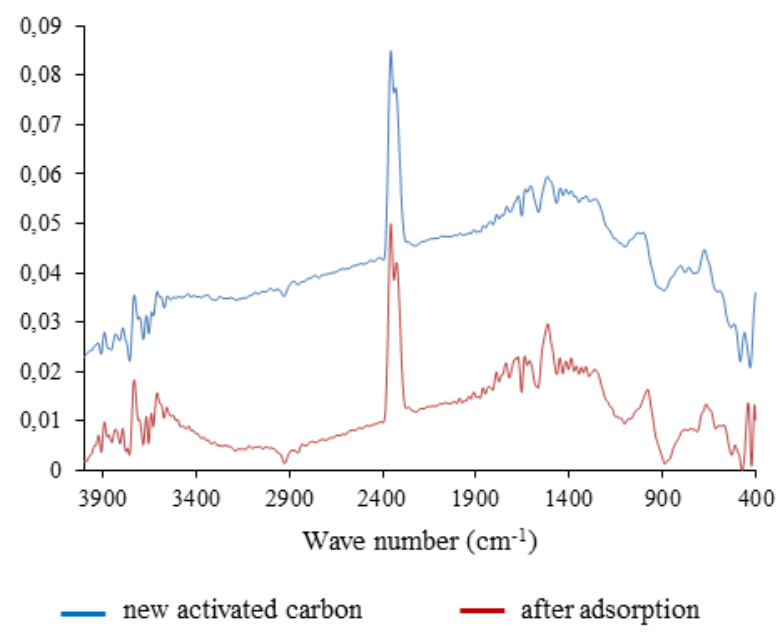

Fig. 6. FTIR new activated carbon and after adsorption

Based on the results of FTIR analysis before and after the activated carbon adsorption (figure 6) can be concluded that the adsorption occurs is physical adsorption, it is not visible from the discovery of new functional groups on the activated carbon after adsorption.

\subsection{Equilibrium studies}
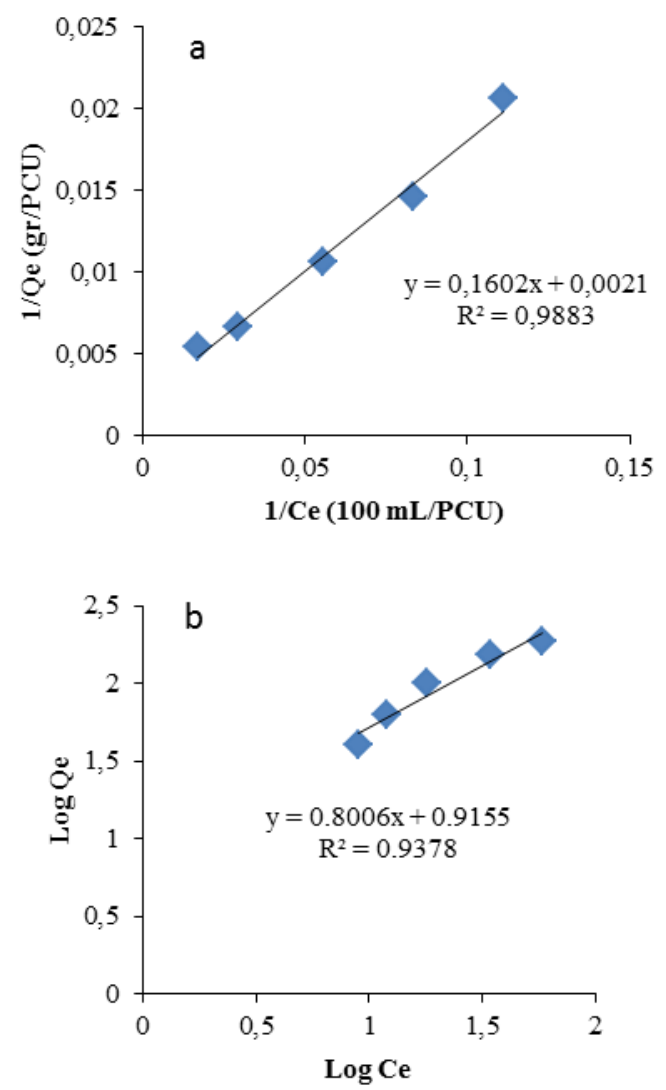

Fig. 7. Langmuir (a) and Freundlich (b) plot for color adsorption

From the equation obtained in the model Langmuir namely $0,1602 \mathrm{x}+\mathrm{y}=0.0021$, we can determine the estimate of the adsorption capacity (Qm) amounted to 476.190 PCU/g of carbon. Langmuir models chosen for this model produced a value greater $\mathrm{R}^{2}$ is 0.9883 , while on the Freundlich models is 0.9378 .

\subsection{Continuous studies}

In the continuous process, using three feed color variants of 59, 77 and 105 PCU, to observe the efficiency and ability of activated carbon in absorbing effluent water color. At the early of the continuous adsorption process, NOM (Natural organic matter) concentration is lower and contributes mainly to the reduction of color caused by micropolutan/organic. Increased flow rate and pressure have a large share in the reduction of color, this is related to the contact time of the adsorption process occurs. Along with the increase in pressure that affects the reduced contact time between the effluent and the adsorbent so as to reduce the efficiency of decreasing color. After a continuous process, pore blocking is more dominant and causes the capacity and kinetics of adsorption to be reduced [20].

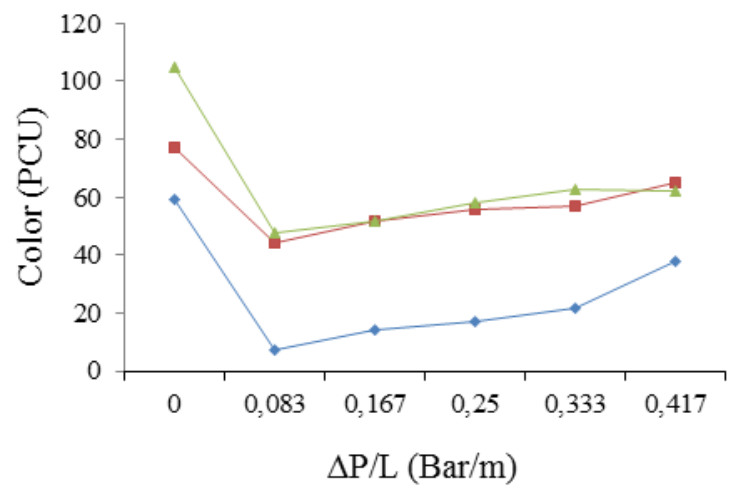

Fig. 8. Water color products on various color feed

At the early process, where $\Delta \mathrm{P} / \mathrm{L} 0.083 \mathrm{Bar} / \mathrm{m}$ with an average contact time of 1,062 minutes have a results output water $48 \mathrm{PCU}$, where the color removal is up to $54,29 \%$ in the $105 \mathrm{PCU}$ feed. Along with the increase in pressure that affects the reduced contact time between the effluent and the adsorbent so as to reduce the efficiency of decreasing color.

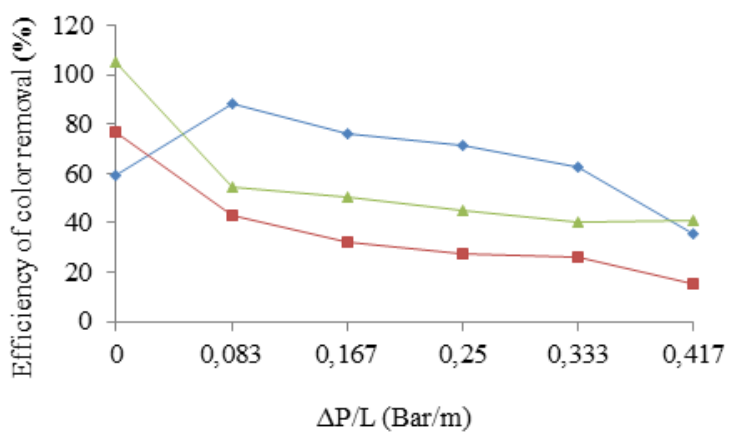

Fig. 9. Efficiency of color removal in various feed 
Efficiency of color removal was $88.14 \%$; 42,86\% and $54,29 \%$, on feed color variation 59, 77 and 105 PCU can be seen in figure 9 . The greatest color removal efficiency in 59 PCU feed is $88,14 \%$ with color output reach 7 PCU, this value even according to PERMENKES drinking water quality standard that is maximum 15 PCU). Pretreatment process should be done first to get color feed lower than color for effluent water STP (105 PCU).

\section{Conclusion}

In the batch process obtained the largest adsorption capacity obtained at 0,5 grams of carbon mass where capacity reached $184 \mathrm{PCU} / \mathrm{g}$ of carbon. Langmuir model is most appropriate to describe the adsorption process isothermis, the maximum adsorption capacity of 476,190 PCU/g of carbon. Based on the results of FTIR analysis before and after the activated carbon adsorption can be concluded that the adsorption occurs is physical adsorption, it is not visible from the discovery of new functional groups on the activated carbon after adsorption. With two justifications the adsorption process that occurs in this study is physical adsorption. Increasing the flow rate and pressure has a big share in the reduction of color in a continuous process, it is related to the contact time of the adsorption process occurs. In $\Delta \mathrm{P} / \mathrm{L} 0083 \mathrm{Bar} / \mathrm{m}$ with an average contact time of 1,062 minutes is the optimum process variables in reducing the color of the synthetic STP effluent water produces 48 PCU.

\section{References}

1. M. A. Gual, Moia, and J.G. March. Journal of Desalination, 219, 81-88 (2008).

2. N. Apostolidis, C. Hertle, and R. Young, Water, ISSN 20173 - 4441 (2011).

3. B. Zhu, and L. Zou, J. Environ. Manage., 90, 3217-3225 (2009).

4. C. N. Sawyer, L. Perry, and F. P. Gene, Chemistry for Environmental Engineering and Science. $\left(\mathbf{5}^{\text {th }}\right.$ edition. Mc Graw Hill Companies, Inc., 2003).

5. R. Bulan, S. S. Mersi, and Darnianti. Indo. J. Chem. (2010).

6. S. Sirianuntapiboon, O. Sadahiro, and P. Salee, J. Environ. Manage., 85, 162-170 (2007).

7. S. A. Al-Mamari, and D. G. Rao, Journal International Environmental Application \& Science, 8, 553-540 (2015).

8. A. Yadav, S. Mukherji, and A. Garg, Ind. Eng. Chem. Res.. (2013).

9. K. W. Jung, M. J. Hwang, D. S. Park, and K. H. Ahn, Sep. Purif. Technol., 146, 154-167 (2015).

10. K. Y. Kim, H. Y. Kim, J. Kim, J. W. Nam, J. M. Kim, S. Son, Desalination, 243, 132 - 144 (2009).
11. J. Altmann, A. S. Ruhl, F. Zietzchmann, Water Res., 185-193 (2014).

12. J. Altmann, F. Zietzschmann, E-L. Geiling, A. S. Ruhl, A. Sperlich, and M. Jekel, Chemosphere, 125, 198-204 (2015).

13. J. Altmann, D. Rehfeld, K. Träder, A. Sperlich, and M. Jekel, Water Res., 92, 131-139 (2016)

14. F. Bonvin, L. Jost, L. Randin, E. Bonvin, and T. Kohn, Water Res., 90, 90-99 (2016).

15. G. Knopp, C. Prasse, T. A. Ternes, and P. Cornel, Water Res., 100, 580-592 (2016).

16. Y. Matsui, S. Nakao, A. Sakamoto, T. Taniguchi, L. Pan, T. Matsushita, and N. Shirasaki, Water Res., 85, 95-102 (2015).

17. Metcalf and Eddy. Wastewater Engineering Treatment and Reuse. $4^{\text {th }}$ edition. New York : Mc Graw-Hill Companies, Inc. (2003).

18. A. W. Zularisam, A. F. Ismail, and R. Salim, Desalination, 194, 211-231 (2006).

19. K. W. Jung, B. H. Choi, M. J. Hwang, T. U. Jeong, and K. H. Ahn, Bioresour. Technol., 219, 185-195 (2016).

20. J. Hu, S. Ran, B. Heijman, dan L. Rietveld, J. Env. Manage. 160, 98-104 (2015). 